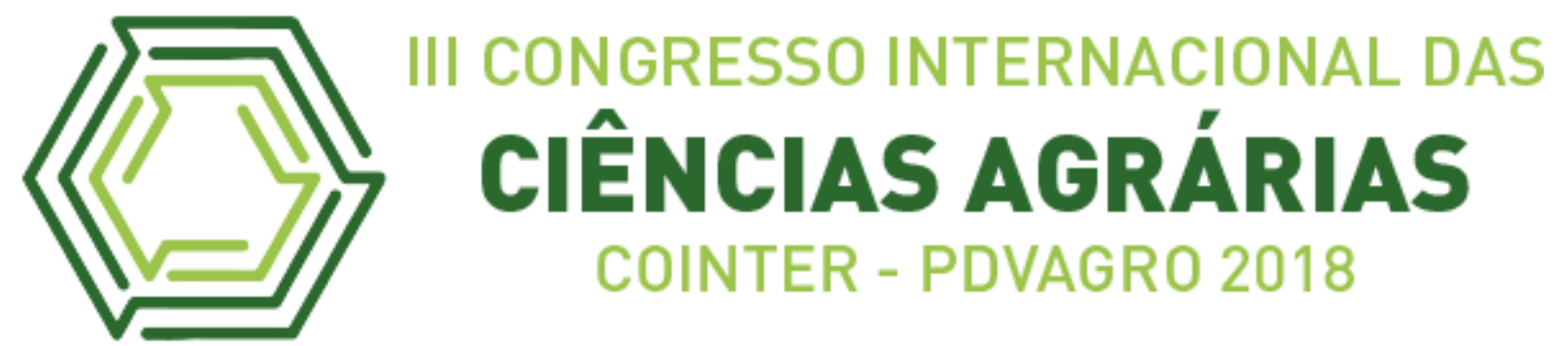

\title{
METODOLOGIA PARA SEMEADURA DE COENTRO COM EQUIPAMENTO DE BAIXO CUSTO
}

\section{METHODOLOGY FOR SOWING CORIANDER WITH LOW COST EQUIPMENT \\ Apresentação: Pôster}

Jhemyson Jhonathan da Silveira Reis ${ }^{1}$; Igor Thiago dos Santos Gomes ${ }^{2}$; Janiel Silva dos Santos $^{3}$; Bárbara Maísa Nunes Araújo ${ }^{4}$; Pablo Radamés Cabral de França ${ }^{5}$

DOI: https://doi.org/10.31692/2526-7701.IIICOINTERPDVAGRO.2018.00570

\section{Introdução}

A cultura do coentro (Coriandrum sativum $\mathrm{L}$ ) é uma hortaliça amplamente produzida e consumida no Brasil, sendo de suma relevância socioeconômica, pelo fato do quantitativo de produtores envolvidos na sua exploração, certamente sendo uma fonte de renda para pequenos e grandes agricultores, mesmo os que não possuem acesso a recursos tecnológicos de produção. Segundo Pereira et al. (2005), as sementes de coentro são de importância significativa e valor comercial, por tratar-se de planta condimentar largamente utilizada no Brasil.

Cada vez mais a agricultura familiar faz uso de novas tecnologias para aumento da produção, mais especificamente, na produção de hortaliças, fazendo uso de sementes de alta qualidade e também mecanismos agrícolas que contribuem com a sustentabilidade, beneficiando a economia e a produtividade. Entretanto, apesar de haver diversas tecnologias para maximizar a produção e diminuir o desgaste físico, uma boa parcela dos agricultores ainda opta pela agricultura totalmente manual, fazendo uso de poucas tecnologias, desde o plantio até a colheita.

Desta forma, faz-se necessário desenvolver equipamentos de baixo custo onde proporciona a versatilidade e simplicidade para auxiliar em atividades agrícolas, favorecendo o dia a dia do agricultor, visando a maximização da produção e não menos importante a saúde e bem estar dos trabalhadores do sistema produtivo. Com isso, objetivou-se com o trabalho,

\footnotetext{
${ }^{1}$ Bacharelado em Agrônoma, IFPA, reis.jhemyson@gmail.com

${ }^{2}$ Bacharelado em Agrônoma, IFPA, igorgomes567@yahoo.com.br

${ }^{3}$ Técnico em Agropecuária, silvajaniel25gmail.com

${ }^{4}$ Bacharelado em Agrônoma, IFPA, barbaramaisa12@hotmail.com

${ }^{5}$ Doutor em Agronomia, IFPA, pablo.radames@hotmail.com
} 
avaliar o desempenho de um semeador de baixo custo correlacionando o diâmetro-capacidade (DC), afim de encontrar paramentos de eficiência no número de sementes por metro linear.

\section{Fundamentação teórica}

Visando a maximização da produção e bem-estar dos trabalhadores no sistema produtivo, pesquisas foram realizadas para propor mecanismos e equipamentos agrícolas de baixo custo, visando à aplicação dos conhecimentos ergonômicos e tecnológicos de tal forma a inserir esta prática e conhecimento no dia a dia dos agricultores que não possuem recursos financeiros para adquirir equipamentos e maquinários agrícolas de alto desempenho e custo de aquisição. Tende-se ampliar o conhecimento e práticas ergonômicas na agricultura, de modo que, este conhecimento ainda é pouco aplicado em atividades agrícolas de pequeno porte, devido ao caráter relativamente disperso desta atividade, não somente pela falta de acesso aos saberes acadêmicos e técnicos, mas também, por falta de equipamentos que insiram métodos ergonômicos ao seu manuseio.

A agricultura familiar no Brasil vem ganhando grande importância na economia brasileira, beneficiando novos meios de produção, não apenas para subsistência, mas também para a venda dos produtos, de tal forma que necessita de maior mão de obra, gerando novos empregos e fazendo uso de novas tecnologias para aumentar a produção. Segundo Nascimento (2012), a agricultura familiar é responsável por $37,9 \%$ da produção agrícola, disponíveis em 107,8 milhões de hectares, e são responsáveis por 50,9\% da renda agrícola. Deste modo, a agricultura familiar se torna mais ampla definindo seu espaço na economia brasileira.

A prática da horticultura representa uma parcela expressiva na agricultura, alcançando altos índices de produção. Segundo pesquisas realizadas pela Companhia nacional de abastecimento - CONAB (2018), destacou que a produção anual brasileira de hortaliças no ano de 2018 chegou a média mensal de 350.000 toneladas, movimentando no mercado acima de 8 bilhões de reais. De tal modo, as hortaliças estão presentes diariamente na mesa dos brasileiros, sendo de grande importância não apenas na economia, mais também nas necessidades nutricionais diárias dos consumidores, facilitando a digestão dos alimentos e favorecendo a saúde dos consumidores.

A grande diversidade de maquinários para a semeadura disponíveis no mercado, e o alto valor dessas maquinas estão restritas a grandes produtores e cooperativas. A necessidade 
de tecnologias eficientes e baixo custo são muito requisitadas por pequenos e médios agricultores, as particularidades encontradas em campo durante a semeadura, variando dentre o tipo de semente até a forma de semeio. A confecção de equipamentos a partir de materiais de baixo, e que podem ser encontrados e reutilizados para a fabricação de equipamentos agrícolas, como por exemplo: semeadores, adubadoras, escarificador e entre outros, quem podem auxiliar e melhorar o desempenha e tempo realizado para desenvolver as atividades de campo, eficiência no quantidade de sementes utilizadas na semeadura, gerando uma economia de sementes por hectare

\section{Metodologia}

O experimento foi conduzido no Instituto Federal do Pará - IFPA, Campus Castanhal, no Setor de Mecanização Agrícola. Para o presente experimento foram utilizadas sementes comerciais de coentro (C. sativum L.) cultivar Verdão, e um semeador de coentro de fluxo contínuo com diferentes diâmetros e capacidades desenvolvido pelos autores.

Após a confecção do semeador, avaliou-se a eficiência do equipamento em função da capacidade de sementes presente no equipamento (40,60 e 80\%) e os diferentes diâmetros de furos dos anéis de regulagem $(6,7$ e $8 \mathrm{~mm})$. Assim, foram determinados sua influência nos parâmetros de quantidade de sementes distribuídas em um metro linear e o número de sementes perdidas por

\section{Resultados e discussões}

Os dados referente aos percentuais das capacidades de 40, 60 e 80\% em função dos diâmetros do semeador de coentro, presentes na Figura 1, mostraram que, quanto maior diâmetro, maior a quantidade de sementes por metro linear. Portanto, todas as diâmetros apresentam uma tendência crescente do número de sementes distribuídas por metro linear.

Segundo França et al (2018a), o quantitativo de sementes e o diâmetro são variáveis que influenciam no consumo de sementes por hectares e na quantidade sementes depositar nos sulcos para a cultura do pimentão, se aproximando da quantidade de sementes utilizadas pelos agricultores do município de Vitória de Santo Antão - PE, com os valor de 53,3 sementes/m com o diâmetro de $8 \mathrm{~mm}$, e com capacidade de $25 \%$.

A quantidade de sementes por metro linear de $7 \mathrm{~mm}$ e $8 \mathrm{~mm}$, com capacidades de $60 \%$ e $80 \%$ apresentaram as maiores quantidades de sementes distribuídas, ficando entre o quantitativo de sementes utilizada por Aguiar et al.(2016), no trabalho de desempenho 
agronômico do coentro, onde foi adotado um valor médio de 153 sementes por metro linear. O orifício de $6 \mathrm{~mm}$ apresentou valores inferiores ao valor médio citado por Aguiar, contendo um número menor de sementes por metro linear.

Figura 1: Regressão linear do número de sementes em um metro linear em função dos diâmetros dos anéis do semeador e da capacidade de sementes no cilindro.

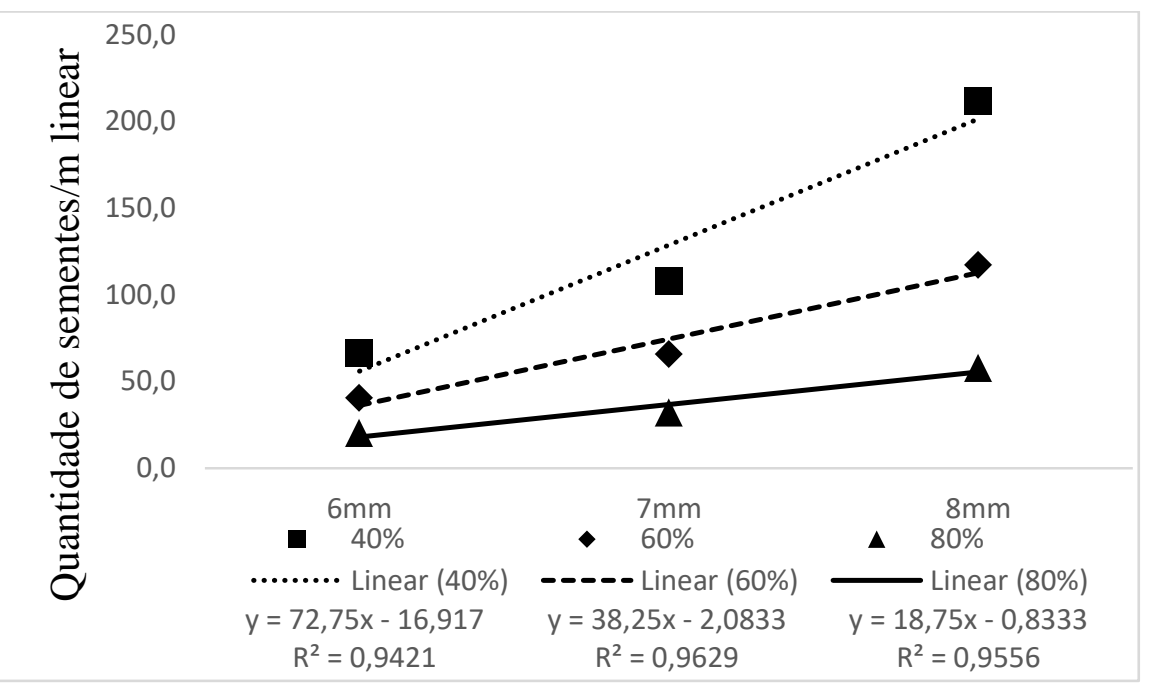

Quanto ao número de sementes perdidas em função das capacidades e diâmetros (Figura 2), mais uma vez ao avaliar os diâmetros de 7 e $8 \mathrm{~mm}$, em capacidades de 60 e $80 \%$ apresentaram uma redução de perdas, quando correlacionado os diâmetros e capacidades. Para a cultura do nabo objetivou-se valores de maior eficiência para a semeadura, reduzindo gastos excessivos e reduzindo o percentual de desbastes, gerando economia e melhor aproveitamento (FRANÇA et al, 2018b).

A perda de sementes resulta em desperdícios, que geram prejuízos ao produtor, semente que poderiam ser utilizadas para cultivar uma quantidade maior de linhas, podendo ter um aproveitamento e eficiência melhor durante o processo de cultivo.

Figura 2: Regressão polinomial do número de sementes pedidas em um metro linear em função dos diâmetros dos anéis perfurados do semeador e da capacidade de sementes no cilindro. 


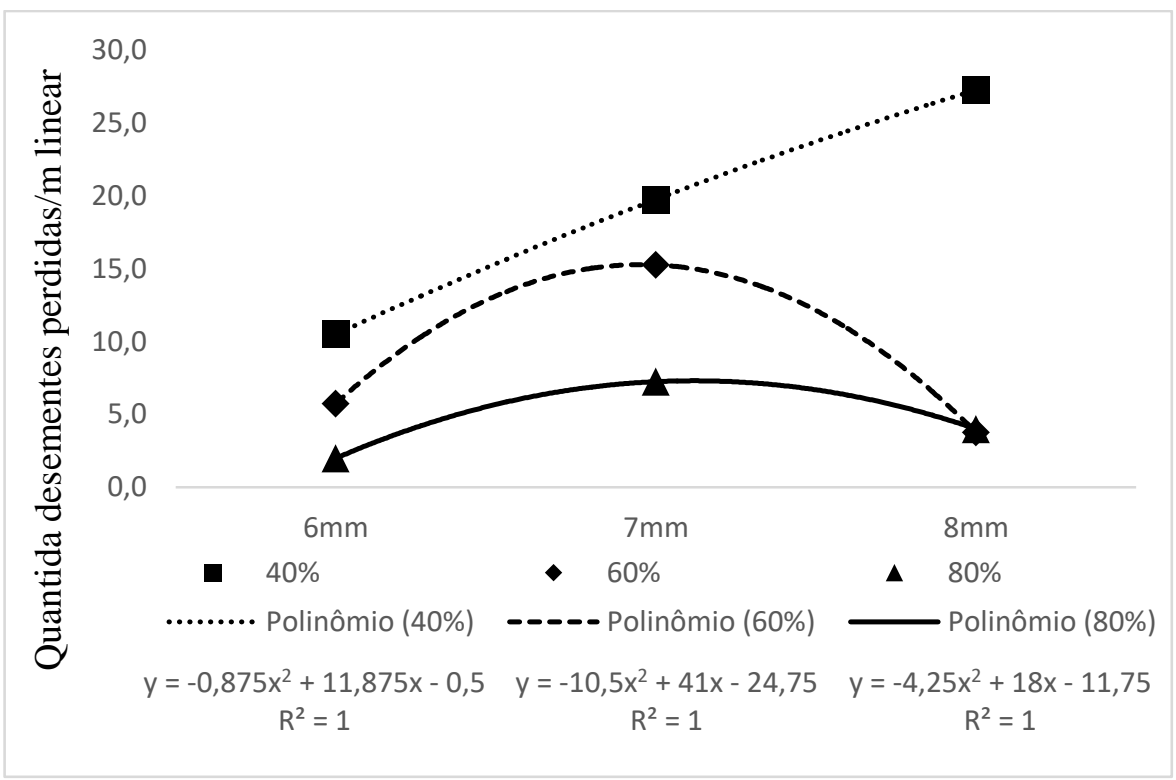

\section{Conclusão}

Com base nas análises de desempenho e possível concluir que o diâmetro dos furos dos anéis do semeador e suas capacidades influenciam diretamente na quantidade de sementes distribuídas em um metro linear. Logo, a determinação de um quantitativo médio de sementes pode ser levando em consideração quando se objetiva uma eficiência no processo de semeadura, podendo ser adotados para operação, diâmetros de 7 e 8 mm com 60 e $80 \%$ da capacidade operacional, além de conter um quantitativo de desperdício de sementes relativamente baixo por metro linear.

\section{Referencias}

AGUIAR, A. M.; SOUZA, J. E. A.; CARVALHO, R. F.; FERREIRA, C. A S.; FERREIRA, C. P. Produção de coentro (Coriandrum sativum L.) cultivado com composto orgânico em Irituia-Pará. Cadernos de Agroecologia, [S.1.], v. 10, n.3, may 2016 ISSN 22367934. Disponivel em:<http://revistas.aba.agroecologia.org.br/index.php/cad/article/view/19812>. Acesso em: 20 sep. 2018.

CONAB - COMPANHIA NACIONAL DE ABASTECIMENTO. Boletim hortigranjeiro volume 4, número 3. Março - 2018.

FRANÇA P. R. C; PERÔNICO B. W. C; UYEDA C. A; ALMEIDA A. R; MIRANDA M. F. A. 2018a. Semeadura semimecanizada para nabo. In: CONGRESSO BRASILEIRO DE OLERICULTURA, 55. Anais... Bonito-MS: ABH. 
FRANÇA P. R. C; PERÔNICO B. W. C; ALMEIDA A. R; MIRANDA M. F. A; UYEDA C. A. 2018b. Metodologia para semeadura de pimentão. In: CONGRESSO BRASILEIRO DE OLERICULTURA, 55. Anais... Bonito-MS: ABH.

NASCIMENTO, W. M. - Produção de sementes de hortaliças para a agricultura familiar - XII Curso sobre Tecnologia de Produção de Sementes de Hortaliças. Mossoró, 2012. 23p.

PEREIRA, R. S; MUNIZ, M. F. B.; NASCIMENTO, W. M. Aspectos relacionados à qualidade de sementes de coentro. Horticultura Brasileira, Brasília, v.23, n.3, p.703-706, jul-set 2005 . 